\title{
Atypical depression in growth hormone deficient adults, and the beneficial effects of growth hormone treatment on depression and quality of life
}

\author{
Tripti Mahajan ${ }^{1}$, Anna Crown ${ }^{1}$, Stuart Checkley ${ }^{2}$, Anne Farmer ${ }^{2}$ and Stafford Lightman ${ }^{1}$ \\ ${ }^{1}$ Henry Wellcome Laboratories for Integrative Neuroscience and Endocrinology, University of Bristol, Bristol, UK and ${ }^{2}$ Institute of Psychiatry, \\ London, UK
}

(Correspondence should be addressed to S Lightman, Henry Wellcome Laboratories for Integrative Neuroscience and Endocrinology, University of Bristol, Dorothy Hodgkin Building, Whitson St, Bristol BS1 3NY, UK; Email: Stafford.Lightman@bristol.ac.uk)

\begin{abstract}
Objective: Some growth hormone deficient adults (GHDAs) have an impaired quality of life, which may improve with growth hormone $(\mathrm{GH})$ treatment. The objective of our study was to make an in-depth psychiatric evaluation of patients with adult-onset (AO) and childhood-onset (CO) GH deficiency (GHD), and to assess the time course of changes in their quality of life and symptoms of depression in response to $\mathrm{GH}$ treatment.

Design: The study design was a 4-month, double-blind, cross-over, placebo-controlled trial of GH therapy.

Methods: We used a detailed psychiatric interview to characterise 25 patients with proven GHD at baseline. They were reassessed at monthly intervals during treatment with $\mathrm{GH}$ or placebo, using the Nottingham Health Profile and two well-recognised depression rating scales.

Results: $11 / 18$ (61\%) of the patients with AO-GHD, but $0 / 7$ of the patients with CO-GHD, were found to have atypical depression at baseline. There were significant improvements in the depression rating scale scores after 2 months of GH therapy, with significant improvements in emotional reaction and social isolation scores from 1 month, and in energy levels and sleep disturbance from 2 and 3 months respectively.

Conclusions: The results of our study confirm that a large proportion of GHDAs have unequivocal psychiatric morbidity, and suggest that a response to treatment can be seen after a short trial of GH therapy. We hypothesise that this rapid improvement of symptoms of atypical depression represents a direct central effect of GH therapy.
\end{abstract}

\section{European Journal of Endocrinology $151325-332$}

\section{Introduction}

It is well recognised that for some hypopituitary patients, growth hormone deficiency (GHD) has an adverse effect on their quality of life (QOL) (1). Symptoms such as reduced energy levels, sleep disturbance, depressed mood, anxiety, and social isolation have been shown to improve with growth hormone $(\mathrm{GH})$ treatment in most, but not all, studies (2). There are many possible causes of impaired QOL in growth hormone deficient adults (GHDAs). There is suggestive evidence that GHD has direct effects on the central nervous system (CNS). Growth hormone treatment of GHDAs reduces the cerebrospinal fluid (CSF) concentrations of vasoactive intestinal peptide and of the dopamine metabolite, homovanillic acid (3, 4), and may increase the CSF concentration of beta-endorphin (4) (although some researchers have found no effect (3)). However, GHD does not seem to alter the CSF levels of 5-hydroxytryptophan (5HT) or norepinephrine (NE) metabolites $(3,4)$, which are usually thought to be the most significant monoamines in depression. Blunting of the GH response to provocation tests has been reported as a feature of major depression in non-GH deficient patients $(5-7)$. GH treatment of GHDAs may also have indirect effects on QOL through effects on body composition, muscle strength and exercise tolerance (1). Finally, confounding factors unrelated to GHD per se may adversely affect QOL in hypopituitary patients. These include the unphysiological substitution of other deficient hormones, neurosurgery (especially transfrontal surgery), cerebral radiotherapy, visual impairment, and the effects of having a chronic disease (8).

There are many reasons for the heterogeneous results of studies of the effect of GH treatment on the QOL of GHDAs. These include patient selection, GH treatment regimens, the heterogeneity of the patients, diagnosis of GHD and assessment of QOL. Some studies use unselected patients, including those with no perceived impairment of QOL, whilst others select those with most symptoms at baseline, or use self-selected 'volunteers' who are also likely to be more symptomatic 
(9). The use of unselected GHDAs may dilute the effects of GH treatment, especially if the tools used to assess QOL show no baseline impairment, whilst the use of selected GHDAs may affect the generalisability of the results to the clinic population of GHDAs. Historically, different GH treatment regimens have been used, starting with either high or low GH doses, and then titrating the dose to the insulin-like growth factor (IGF)-I concentration. Whilst high doses may result in supra-physiological IGF-I concentrations, low doses may not result in significant increments in the IGF-I concentration of some GHDAs (2). The lengths of treatment and of washout periods have also varied, and some studies have been placebo controlled, whilst others have been open label and liable to a 'placebo effect'. Even with placebo-controlled trials, the side-effects of GH treatment potentially negate the effects of blinding, by revealing whether the subject is receiving GH or placebo (10). This may result in bias on the part of the observer and of the subjects, who are likely to be aware of the hypothesis being tested. The patients are heterogeneous, varying in their original pituitary pathology, its treatment, age at onset and other pituitary hormone deficiencies. Different ways of diagnosing GHD have been used, including 'likely GHD', the IGF-I concentration, and different GH provocation tests with different cut-offs. Regarding the assessment of QOL, some studies have used the 'disease specific' Adult Growth Hormone Deficiency Assessment (AGHDA) questionnaire (11) whilst others have used generic questionnaires. It has been proposed that the AGHDA is more sensitive to the specific symptoms of GHD (that are reversible by treatment), but this could become a circular argument. Barkan has also shown that the 'disease specific' questionnaire could not distinguish between unsubstituted GH deficiency and GH excess (active acromegaly) (12).

The main aims of this study were to find out if GHDAs fulfilled the criteria for any specific psychiatric diagnoses, and to investigate the effect of $\mathrm{GH}$ treatment on depression and QOL in GHDAs. A subsidiary aim was to compare the use of a simple self-assessment questionnaire to screen for psychiatric diagnoses in GHDAs with observer assessment using depression rating scales administered by a trained interviewer. We used a placebo-controlled, double-blind, cross-over design, starting with a detailed baseline psychiatric assessment of the patients. In a number of the study subjects, this yielded the diagnosis of atypical depression. Patients with childhood-onset (CO) GH deficiency were relatively asymptomatic compared with those with adult onset (AO) GH deficiency. We used well-validated, reliable tools to assess changes in QOL and severity of depression. We showed that GH treatment had a rapid effect on the components of the atypical depression, including emotional reactivity, social isolation and fatigue, improving these symptoms within a few months.

\section{Subjects and methods}

\section{Patients}

The local research ethics committee approved the study, and all subjects gave written, informed consent. All patients with hypothalamic/pituitary disease under the care of the Endocrinology Department of the Bristol Royal Infirmary over a 5-year period were invited to take part in a study of the diagnosis of GHD (13). Those who volunteered to take part in that study and were found to be $\mathrm{GH}$ deficient were then invited to take part in the current trial. Exclusion criteria included pregnancy or lactation, and a diagnosis of acromegaly or Cushing's disease. Those who volunteered underwent an insulin tolerance test (ITT) or a growth hormone releasing hormone/growth hormone releasing peptide-2 (GHRH/GHRP) stimulation test if an ITT was contraindicated, as previously described (13). GH deficiency was defined as a peak GH response to the ITT of less than $9 \mathrm{mU} / \mathrm{l}$, or a peak GH response to the GHRH/GHRP test of less than $17 \mathrm{mU} / \mathrm{l}$. The first 25 patients with GHD were recruited for the study (16 male, nine female, age range $18-59$ years, mean 38.4 years, median 39 years). Their details are shown in Table 1. Their diagnoses included ten nonfunctioning adenoma, five craniopharyngioma, three macroprolactinoma, two gonadotrophinoma, one parameningeal sarcoma, one Rathke's pouch cyst, one empty sella syndrome, and two idiopathic GHD. Fourteen patients were also deficient in thyrotrophin (TSH), adrenocorticotrophin (ACTH) and luteinising hormone/follicle-stimulating hormone (LH/FSH), five had two other pituitary hormone deficiencies, four had one other pituitary hormone deficiency, and two had isolated GH deficiency. Eighteen patients (mean age 42.4 years) had adult-onset GH deficiency (AO-GHD), and seven patients (mean age 28.1 years) had childhood-onset GH deficiency (CO-GHD). Twenty-one patients had had pituitary surgery, of whom eight had also had pituitary radiotherapy. One patient had had pituitary radiotherapy but no surgery. All patients with other pituitary hormone deficiencies had been on optimal hormone replacement therapy for at least three months prior to testing. None of the patients on glucocorticoid replacement therapy were on a supraphysiological dose (more than $20 \mathrm{mg}$ hydrocortisone daily), and none had received $\mathrm{GH}$ for at least one year. Two patients were taking antidepressants before the study, and continued to take the same medication at the same dose throughout.

\section{Treatment protocol}

The study was a four-month, double-blind, placebocontrolled crossover trial, with a four-month washout period. Patients were randomly assigned to receive either recombinant human growth hormone (Genotropin, Pharmacia, UK) or placebo. The initial dose was 
Table 1 Details of study patients.

\begin{tabular}{|c|c|c|c|c|c|c|c|c|c|}
\hline \multirow[b]{2}{*}{$\mathrm{AO} / \mathrm{CO}$} & \multirow[b]{2}{*}{ Age (years) } & \multirow[b]{2}{*}{ Gender (M/F) } & \multirow[b]{2}{*}{ GHD (years) } & \multirow[b]{2}{*}{ Surgery } & \multirow[b]{2}{*}{ DXT } & \multicolumn{3}{|c|}{$\begin{array}{l}\text { Other pituitary } \\
\text { deficiencies }\end{array}$} & \multirow[b]{2}{*}{ Diagnosis } \\
\hline & & & & & & TSH & $\mathrm{ACTH}$ & $\mathrm{LH} / \mathrm{FSH}$ & \\
\hline $\mathrm{CO}$ & 18 & $\mathrm{~F}$ & 7 & $\mathrm{Y}$ & $\mathrm{N}$ & $\mathrm{Y}$ & Y & Y & Craniopharyngioma \\
\hline $\mathrm{CO}$ & 18 & M & 6 & $\mathrm{Y}$ & $\mathrm{Y}$ & $\mathrm{Y}$ & $\mathrm{N}$ & Y & Parameningeal sarcoma \\
\hline $\mathrm{CO}$ & 19 & $\mathrm{~F}$ & 10 & $\mathrm{~N}$ & $\mathrm{~N}$ & $\mathrm{Y}$ & $\mathrm{N}$ & Y & Empty sella syndrome \\
\hline $\mathrm{CO}$ & 21 & M & 19 & $\mathrm{Y}$ & $\mathrm{N}$ & $\mathrm{Y}$ & $\mathrm{Y}$ & $\mathrm{Y}$ & Craniopharyngioma \\
\hline $\mathrm{CO}$ & 36 & $\mathrm{~F}$ & 21 & $\mathrm{Y}$ & $\mathrm{Y}$ & $\mathrm{Y}$ & $\mathrm{Y}$ & Y & Inactive adenoma \\
\hline $\mathrm{CO}$ & 37 & M & 30 & $\mathrm{~N}$ & $\mathrm{~N}$ & $\mathrm{~N}$ & $\mathrm{~N}$ & $\mathrm{~N}$ & Idiopathic GHD \\
\hline $\mathrm{CO}$ & 48 & $\mathrm{~F}$ & 20 & $\mathrm{Y}$ & $\mathrm{N}$ & $\mathrm{Y}$ & $\mathrm{Y}$ & $\mathrm{Y}$ & Craniopharyngioma \\
\hline $\mathrm{AO}$ & 23 & M & 3 & $\mathrm{~N}$ & $\mathrm{Y}$ & $\mathrm{Y}$ & $\mathrm{Y}$ & Y & Macroprolactinoma \\
\hline $\mathrm{AO}$ & 26 & M & 2 & $\mathrm{Y}$ & $\mathrm{N}$ & $\mathrm{Y}$ & $\mathrm{Y}$ & Y & Craniopharyngioma \\
\hline $\mathrm{AO}$ & 26 & M & 3 & $\mathrm{Y}$ & $\mathrm{N}$ & $\mathrm{Y}$ & $\mathrm{Y}$ & Y & Macroprolactinoma \\
\hline $\mathrm{AO}$ & 34 & $\mathrm{~F}$ & 4 & $\mathrm{Y}$ & $\mathrm{N}$ & $\mathrm{N}$ & $\mathrm{N}$ & Y & Inactive adenoma \\
\hline AO & 38 & M & 9 & $\mathrm{Y}$ & $\mathrm{Y}$ & $\mathrm{Y}$ & $\mathrm{Y}$ & Y & Inactive adenoma \\
\hline $\mathrm{AO}$ & 38 & $\mathrm{~F}$ & 2 & $\mathrm{Y}$ & $\mathrm{N}$ & $\mathrm{N}$ & $\mathrm{N}$ & Y & Inactive adenoma \\
\hline $\mathrm{AO}$ & 39 & M & 4 & $\mathrm{~N}$ & $\mathrm{~N}$ & $\mathrm{~N}$ & $\mathrm{~N}$ & Y & Idiopathic hypopituitarism \\
\hline $\mathrm{AO}$ & 39 & $\mathrm{~F}$ & 5 & $\mathrm{Y}$ & $\mathrm{Y}$ & $\mathrm{Y}$ & $\mathrm{Y}$ & Y & Inactive adenoma \\
\hline $\mathrm{AO}$ & 39 & M & 6 & $\mathrm{Y}$ & $\mathrm{N}$ & $\mathrm{Y}$ & $\mathrm{N}$ & Y & Macroprolactinoma \\
\hline $\mathrm{AO}$ & 44 & $\mathrm{~F}$ & 11 & $Y$ & $\mathrm{~N}$ & $\mathrm{Y}$ & $\mathrm{Y}$ & $\mathrm{Y}$ & Rathke's pouch cyst \\
\hline $\mathrm{AO}$ & 44 & M & 2 & $\mathrm{Y}$ & $\mathrm{Y}$ & $\mathrm{N}$ & $\mathrm{N}$ & Y & Inactive adenoma \\
\hline $\mathrm{AO}$ & 46 & M & 5 & $\mathrm{Y}$ & $\mathrm{Y}$ & $\mathrm{Y}$ & $\mathrm{N}$ & Y & Inactive adenoma \\
\hline $\mathrm{AO}$ & 52 & M & 1 & $\mathrm{Y}$ & $\mathrm{N}$ & $\mathrm{Y}$ & $\mathrm{N}$ & $\mathrm{Y}$ & Gonadotrophinoma \\
\hline $\mathrm{AO}$ & 52 & $\mathrm{M}$ & 2 & $\mathrm{Y}$ & $\mathrm{N}$ & $\mathrm{Y}$ & $\mathrm{Y}$ & $\mathrm{Y}$ & Craniopharyngioma \\
\hline $\mathrm{AO}$ & 52 & M & 4 & Y & $\mathrm{Y}$ & $\mathrm{Y}$ & $\mathrm{Y}$ & Y & Inactive adenoma \\
\hline $\mathrm{AO}$ & 56 & $\mathrm{~F}$ & 10 & $\mathrm{Y}$ & $\mathrm{N}$ & $\mathrm{Y}$ & $\mathrm{Y}$ & $\mathrm{Y}$ & Inactive adenoma \\
\hline $\mathrm{AO}$ & 57 & M & 1 & $\mathrm{Y}$ & $\mathrm{N}$ & $\mathrm{Y}$ & $\mathrm{Y}$ & Y & Gonadotrophinoma \\
\hline $\mathrm{AO}$ & 59 & M & 3 & $\mathrm{Y}$ & $\mathrm{Y}$ & $\mathrm{N}$ & $\mathrm{N}$ & $\mathrm{N}$ & Inactive adenoma \\
\hline
\end{tabular}

DXT, external pituitary radiotherapy treatment.

$0.125 \mathrm{U} / \mathrm{kg} /$ week (0.04 mg/kg/week), divided into seven daily injections given at bedtime, and increased to $0.25 \mathrm{U} / \mathrm{kg} /$ week $(0.08 \mathrm{mg} / \mathrm{kg} /$ week $)$ after the first month, to a maximum of $4 \mathrm{U}(1.3 \mathrm{mg})$ daily. The dose was adjusted each month by $1 \mathrm{U} /$ day (in patients with daily doses of greater than $2.5 \mathrm{U}$ daily) or $0.5 \mathrm{U} /$ day (in patients with daily doses of less than $2.5 \mathrm{U}$ daily), to maintain the serum IGF-I concentrations within the age- and sex-related reference range.

This was in accordance with the GH treatment protocol in use when the trial started. The dose of placebo was adjusted in the same way, to a maximum equivalent dose of $4 \mathrm{U}$ daily. A research nurse who was not otherwise involved in the study carried out any necessary dose adjustments.

\section{Assessment of quality of life and symptoms of depression}

At entry to the study, subjects completed the General Health Questionnaire-28 (GHQ-28) (14), which is a short self-administered questionnaire used to screen for psychiatric disorders. The 'corrected-GHQ' (CGHQ) scoring method was used, which has increased sensitivity to detect chronic conditions (15). A higher score reflects an increased probability of an underlying psychiatric disorder. At baseline, subjects also underwent a detailed psychiatric evaluation, using the Schedules for Clinical Assessment in Neuropsychiatry (SCAN) (16). This structured interview, conducted by a SCAN-trained interviewer, assesses a wide range of symptoms that may be related to psychiatric disorders. The data were analysed using the CATEGO5 scoring program, which relates the symptom scores to algorithms for making specific psychiatric diagnoses according to the International Classification of Diseases, 10th Edition (17).

At baseline, at the beginning and end of each phase of treatment with $\mathrm{GH} /$ placebo, and monthly during each treatment arm, QOL was assessed using the Nottingham Health Profile (NHP). This is a self-rating scale, which is designed to measure perceived health status $(18,19)$. The questions relate to six dimensions: physical mobility, pain, sleep, social isolation, emotional reactions and energy levels. A high score indicates a high degree of impairment. At the same time points, severity of depression and the response to treatment with $\mathrm{GH} /$ placebo was assessed by a trained interviewer using the Hamilton Depression Rating Scale (HDRS) (20) and the Montgomery Asberg Depression Rating Scale (MADRS) (21). The interviewer who administered the HDRS and MADRS was not present during the SCAN interviews, and did not know the SCAN results until the study was completed.

\section{Assays}

Samples were separated immediately using a refrigerated centrifuge $\left(4^{\circ} \mathrm{C}\right)$ and stored at $-20^{\circ} \mathrm{C}$ pending 
analysis. IGF-I was measured by an in-house radioimmunoassay, after formic acid-acetone extraction of serum samples. Cold IGF-II was added to decrease interference by binding proteins. The anti-IGF-I monoclonal antibody (BPL-M23, Blood Products Ltd, Oxford Biotechnologies, Kidlington, Oxford, UK) was used at a final dilution of 1:20 000. The interassay coefficient of variation was $6.2 \%$.

\section{Statistical analysis}

Data from the placebo treatment arms for all patients were combined for analysis, as were data from the $\mathrm{GH}$ treatment arms, irrespective of the order in which the patients received them. Paired $t$-tests were used to compare the means of normally distributed data, and the Wilcoxon Rank Sum test was used to compare the means of data that were not normally distributed. Spearman's correlation coefficient was calculated for non-parametric data. Within-group comparisons were performed by repeated measures analysis of variance (MANOVA procedure using SPSS software) (SPSS, Chicago, IL, USA), followed by paired $t$-tests when differences were detected. A value of $P<0.05$ is taken to indicate statistical significance.

\section{Results}

\section{GH treatment and adverse events}

The average daily dose of GH after titration was $1.9 \mathrm{U}$ $(0.6 \mathrm{mg})$ in male patients and $2.5 \mathrm{U}(0.8 \mathrm{mg})$ in female patients. Three patients developed side effects on GH treatment. Two patients developed arthralgia and paraesthesiae associated with supraphysiological IGF-I concentrations, which resolved when their GH dose was reduced, and one patient had transient painful oedema of the hands with a normal IGF-I concentration, which resolved spontaneously over two weeks. There were no adverse events associated with placebo treatment. None of the patients withdrew from the study or missed any follow-up appointments.

\section{Serum IGF-I concentrations}

Mean serum IGF-I concentrations at baseline were $191.8 \mathrm{ng} / \mathrm{ml}$ in males, and $158.6 \mathrm{ng} / \mathrm{ml}$ in females. By the second month of GH therapy, all patients had IGF-I concentrations within the age- and sex-related reference range (with means of $427.8 \mathrm{ng} / \mathrm{ml}$ in males and $400.6 \mathrm{ng} / \mathrm{ml}$ in females; S.D. $161.9 \mathrm{ng} / \mathrm{ml}$ for all patients on GH therapy). IGF-I concentrations above the age-related reference range were reported on one occasion in two individuals during GH therapy; there were no occasions when the IGF-I concentration on $\mathrm{GH}$ treatment was below the reference range.

\section{Quality of life and depression}

General Health Questionnaire There was no significant difference in the mean $\mathrm{CGHQ}$ scores of patients with AO- and CO-GHD (14.6 and 15.3 respectively). Both groups had a significantly higher CGHQ score than has previously been reported in a normal population (7.81, S.D. 5.65) (15), indicating an increased likelihood of psychiatric morbidity. There were significant correlations between the self-rated CGHQ scores and the baseline HDRS and MADRS scores $(r=0.56$, $P=0.003$, and $r=0.60, P=0.001$ respectively), indicating a high level of correlation between selfassessment and observer-assessment of mood.

Schedules for Clinical Assessment in Neuropsychiatry Analysis of the baseline SCAN data showed that $11 / 18(61 \%)$ of the patients with AO-GHD, but $0 / 7$ of the patients with CO-GHD, had atypical depression. Although the difference between the groups was statistically significant (Chi-squared test with continuity correction $P<0.025)$, there were other differences between them (particularly current age), and small numbers did not permit further
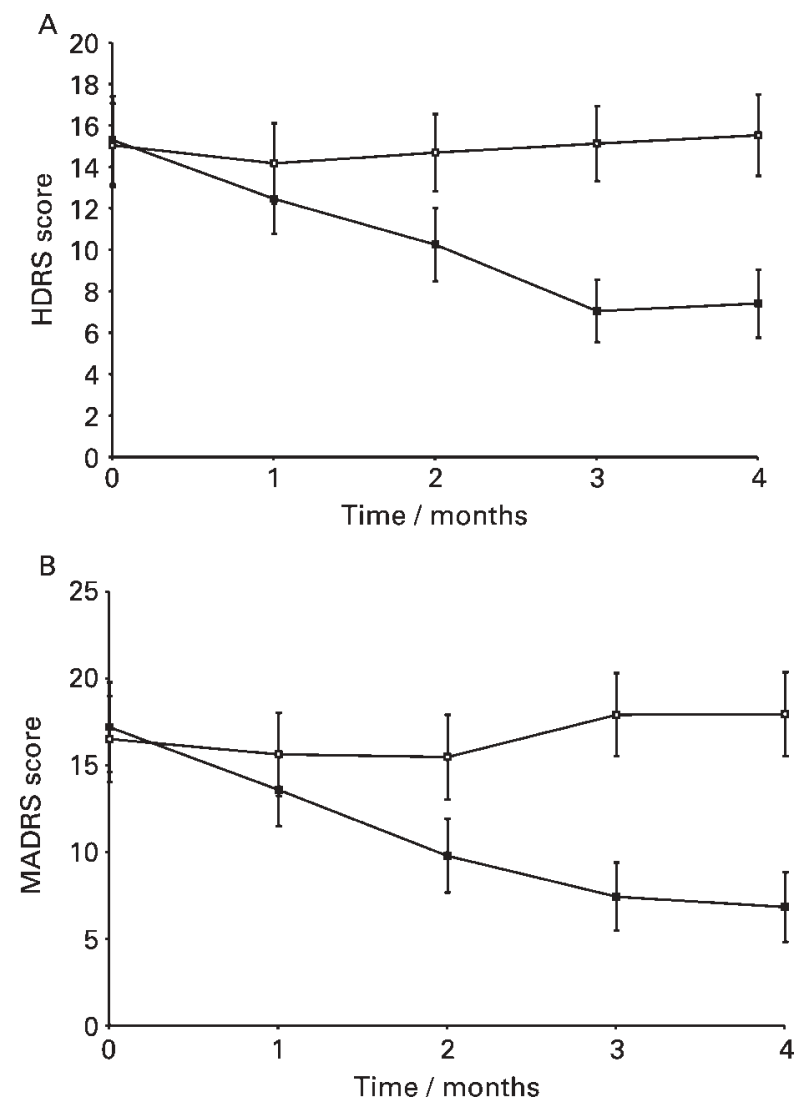

Figure 1 Hamilton Depression Rating Scale (A) and Montgomery Asberg Depression Rating Scale (B) scores, illustrating the response to treatment with growth hormone (.) or placebo ( $)$. Values are presented as means \pm S.E.M. 
sub-group analysis. Other diagnoses obtained from the SCAN included two patients with anxiety disorders (both AO who also had atypical depression), and two patients with sleep disorders (one $\mathrm{CO}$ with no other psychiatric diagnoses, and one AO with both atypical depression and anxiety disorders).

Hamilton and Montgomery Asberg Depression Rating Scales There was a highly significant correlation between the HDRS and the MADRS scores at baseline (Spearman's correlation coefficient $r=0.96$, $P<0.0001)$. Those subjects who were found to have atypical depression using the SCAN had significantly different HDRS and MADRS scores at baseline compared with those who were not (Wilcoxon rank sum $P=0.009$ and $P=0.007$ respectively).

There were no significant differences between the HDRS and MADRS scores of the groups allocated to $\mathrm{GH}$ or placebo at baseline. At 2 months, the HDRS and MADRS scores improved significantly in the GHtreated group compared with those on placebo ( $P<0.017$ and $P<0.001$ respectively). These differences remained highly significant at four months $(P<0.0001$ for both HDRS and MADRS scores). These data are illustrated in Fig. 1A and B.
Nottingham Health Profile The NHP data are illustrated in Fig. 2A-D. There was no significant difference between the baseline scores of the $\mathrm{GH}$ and placebo groups for any of the six dimensions of the NHP. The emotional reaction and social isolation scores decreased with GH treatment, with significant reductions from 1 month $(P<0.03$ and $P<0.006$ respectively). Energy levels improved with GH treatment, with significant differences between the groups from 2 months $(P<0.002)$. From 3 months, the GHtreated group also showed significantly less sleep disturbance $(P<0.02)$. There were no significant differences between the physical mobility and pain scores of the GH- and placebo-treated groups (data not shown).

\section{Discussion}

In this study, we made a detailed baseline psychiatric assessment of 25 GHDAs. Using the SCAN, we found that $60 \%$ of those with $\mathrm{AO}-\mathrm{GHD}$, but none of those with CO-GHD, had atypical depression. The patients then entered a double-blind, placebo-controlled, crossover study of GH treatment. We demonstrated a rapid improvement in depression rating scores with
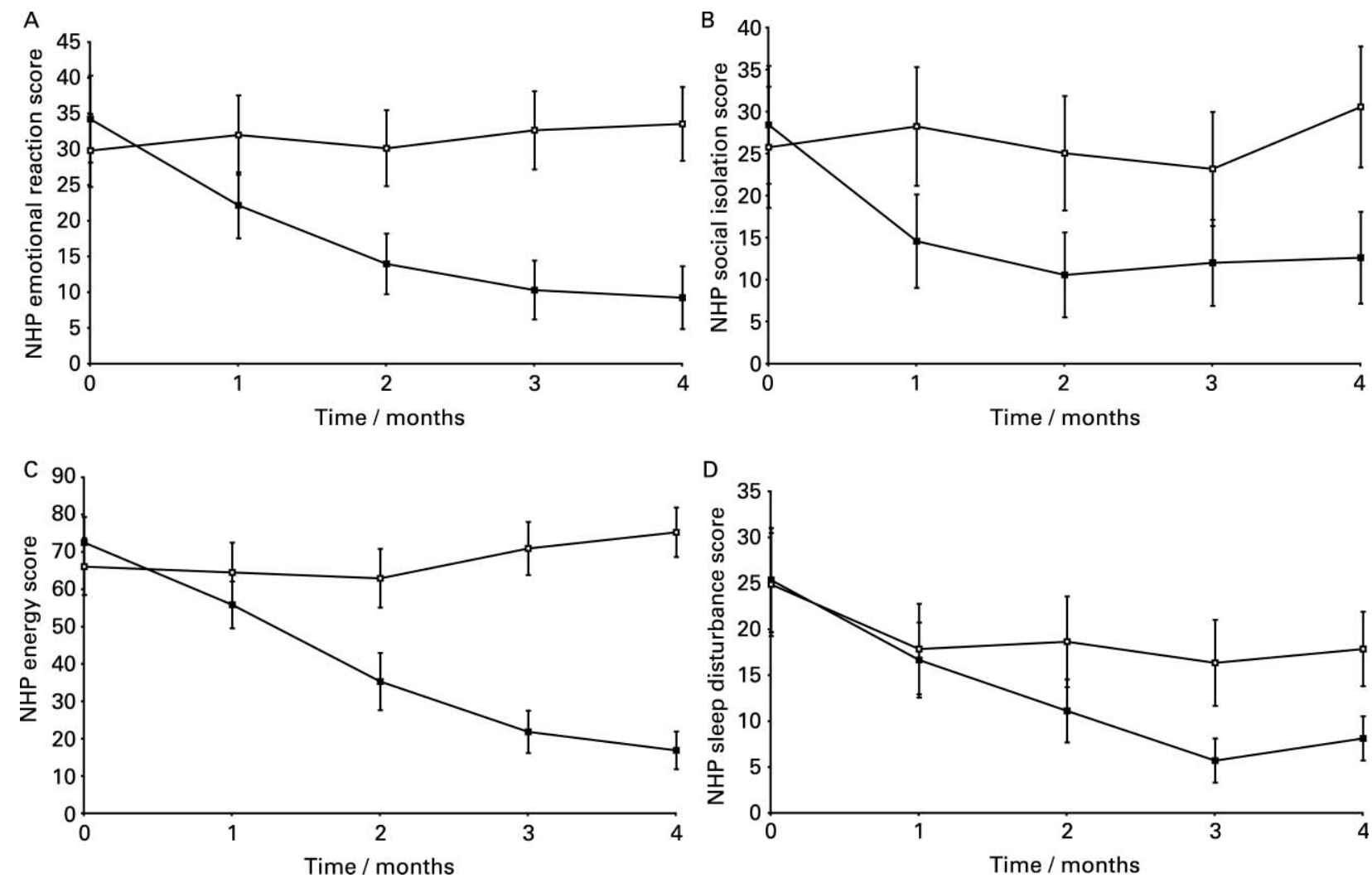

Figure 2 Nottingham Health Profile scores for (A) emotional reaction, (B) social isolation, (C) energy levels and (D) sleep disturbance, illustrating the response to treatment with growth hormone $(\square)$ or placebo $(\square)$. Values are presented as means \pm S.E.M. 
GH treatment, which was statistically significant from 2 months. We also demonstrated improvements in quality of life with GH treatment. The four dimensions of the NHP which showed improved scores with GH treatment probably represent components of the atypical depression. 'Social isolation' captures negative feelings about social situations, which reflects the reduced self-worth and sensitivity to rejection that may be associated with atypical depression. 'Emotional reactions' represent exaggerated forms of the normal reactions to stress. Unlike patients with major depression, the mood of patients with atypical depression is not always low, and will vary in response to events, so that they retain some ability to enjoy life.

Interestingly, the scores for social isolation and emotional reaction showed significant improvements after only 1 month of GH treatment, whilst improved energy levels and reduced sleep disturbance were significant at 2 and 3 months respectively. Physical mobility and pain scores were unaffected by GH treatment. This suggests that the effect of GH treatment on depression was not secondary to the changes in muscle strength or exercise tolerance, which may also accompany GH treatment. The fatigue and sleep disturbance may be a primary phenomenon related to $\mathrm{GH}$ deficiency per se (1), or may be attributable to or associated with the atypical depression. Supportive evidence for the former hypothesis includes the observation that patients with acromegaly have abnormal sleep patterns, which normalise post-operatively (22).

Some features of the study design may have influenced our findings. All the study subjects were volunteers who were informed of the hypothesis being tested. It has been shown that such groups tend to be more symptomatic at baseline than the general clinic population of $\mathrm{GH}$ deficient adults (9). This selection bias does not affect the validity of the results, but does affect their generalisability. We did not select study subjects on the basis of their symptoms of depression or impaired quality of life, and the small numbers did not permit subgroup analysis of the patients with atypical depression. However, the inclusion of only $\mathrm{GH}$ deficient patients with depression would be expected to strengthen the results we report (23). When the study started, protocols for GH therapy in adults started at higher doses than is usual now. However, there were only two occasions when the IGF-I concentration was supraphysiological, and even 'low dose' protocols cannot mimic the physiological pattern of GH secretion. Three patients experienced side-effects of GH treatment, which potentially unblinded both them and the principal investigator by revealing their treatment arm, and could have biased their results. We tried to minimise observer bias by the use of standardised, structured questionnaires. We used a variety of instruments to assess QOL and depression. These included the SCAN and the HRDS and MADRS, which were administered independently by two trained interviewers, and the
GHQ and NHP self-rating scales. The agreement described between these methods of assessment strengthens our findings, and the high level of correlation between self-assessed and observer-assessed mood supports the use of self-reported mood to guide GH therapy. The short GH treatment period and monthly reviews enabled us to follow the time-course of the response. We hypothesised that any direct effect of GH treatment on depression would be seen within 4 months, and that later changes were more likely to be confounded by the indirect effects of $\mathrm{GH}$ treatment on QOL, attributable to changes in body composition.

The observation that none of the patients with CO-GHD had atypical depression, in contrast to $60 \%$ of the patients with AO-GHD, has a number of possible explanations. It may be a Type I statistical error (i.e. there may, in reality, be no difference between the two groups), given that there were only seven patients with CO-GHD in this study. It may have been confounded by other differences between the two groups, including current age. If the result reflects a true difference between patients with CO- and AO-GHD, it may be attributable to their reduced experience of a 'life before' GHD to contrast with their current situation and feelings. Alternatively, compensatory changes in the balance of neurotransmitters may take place during development in patients with CO-GHD, whilst the system is less plastic in adulthood. This area would be a suitable topic for future research; the present study was neither designed nor powered to address it.

A number of investigators have carried out cross-sectional studies to compare the QOL of hypopituitary patients with proven or assumed GH deficiency with that of matched population-based controls. Examples include Bulow et al. (8) who found a higher prevalence of mental disorders and distress in hypopituitary women (relative risk of mental disorders 4.5, 95\% confidence interval 1-21), with reduced social attachment and integration and an increased prevalence of obsessive-compulsive, phobic and psychotic symptoms. Rosen et al. (24) found significant differences between hypopituitary patients and controls in the NHP domains of energy, social isolation and emotional reaction. Peace et al. (25) report more depression, anxiety, and impaired social adjustment in patients with pituitary disease. They also noted unrealistic self-appraisal in patients treated with transfrontal surgery compared with the assessment of a close informant. Other investigators have used patients with other chronic diseases as their control group. Lynch et al. (26) compared patients with pituitary disease with patients with diabetes, and found significantly more pituitary patients fulfilled the Diagnostic and Statistical Manual (DSM)-IIIR criteria for major depression (13/41 pituitary patients compared with $4 / 41$ patients with diabetes, $P<0.001)$. Page et al. (27) used patients who had previous mastoid surgery as their control group. Overall, there was no significant 
difference in QOL, but those pituitary patients treated with radiotherapy had impaired mental health, more depression and decreased control of their emotions (assessed using the Short Form-36 and Psychological General Well-Being (PGWB) questionnaires). Cross-sectional studies of this sort could be confounded by many factors, both related and unrelated to GHD, and this study design cannot define the role of GH deficiency in the aetiology of the psychological symptoms.

Reviewing GH treatment trials with QOL or depression as an end point, many varied protocols have been used, and the results have also been heterogeneous. Examples include McGauley et al. (28) who carried out a randomised, double-blind, placebo-controlled study of GH treatment in GHDAs. At baseline, they found impaired QOL in the GHDAs compared with population controls in the NHP dimensions of energy, emotional reaction and social isolation, and the PGWB scores. After 6 months of GH treatment, they report improved mood and energy levels. Cuneo et al. (29) report the results of the Australian multicentre trial of GH treatment in GHDAs. This was a randomised, double-blind, placebo-controlled trial of $\mathrm{GH}$ treatment for 6 months, followed by 6 months of open-label GH treatment. They found little or no baseline impairment in QOL, although beneficial effects of GH treatment were found in the NHP dimensions of energy, pain and emotional reaction. Murray et al. (30) report the results of an open-label trial of low dose GH. They selected patients who had impaired QOL despite optimal replacement of other pituitary hormones. Using the PGWB questionnaire and the AGHDA, they demonstrated significant improvements in quality of life from 3 months, which were proportional to the baseline degree of impairment. Drake et al. (31) also carried out an open-label $\mathrm{GH}$ treatment trial, with a low starting GH dose followed by GH titration. Using the AGHDA, they found significant improvements in wellbeing from 3 months. Gilchrist et al. (32) report that improvements in QOL are maintained for up to 9 years in patients who choose to continue GH therapy after a trial. In contrast, Whitehead et al. (33) found no improvement in NHP or PGWB scores in their 6month, double-blind placebo-controlled trial of 'high dose' GH therapy. Baum et al. (34) found no change in QOL after 18 months of low dose 'physiological' GH therapy. It has been suggested that the results of these 'negative' studies may be attributable, in part, to the fact that many of the subjects did not report any impairment of their QOL at baseline. Additionally, in the Baum study, it has been noted that not all subjects achieved significant increments in their IGF-I concentration with GH treatment (2). This anomaly may arise because of the use of GH stimulation tests for diagnosis, and IGFI concentrations for monitoring. The optimum IGF-I target (within the standardised normal range) is not known, given that 'physiological' GH replacement therapy is not possible.
As rationing of medical interventions is now acknowledged, it is vital to weigh up all the evidence regarding GH treatment of GHDAs. All of the patients in our study had proven GH deficiency defined by their response to $\mathrm{GH}$ provocation tests. Based on the results of a detailed diagnostic interview (SCAN) we found that $60 \%$ of the adult-onset GH deficient patients had an atypical depression, characterised by emotional reactivity, social isolation, fatigue and sleep disturbance. None of the 7 patients with childhood-onset GH deficiency was found to have atypical depression. Using a combination of well-recognised methods of assessment of QOL and depression, including structured interviews and self-rated questionnaires, we showed that there was a rapid response to GH therapy, over a few months of treatment, which was unlikely to be attributable to the indirect effects of $\mathrm{GH}$ treatment on QOL. As far as possible, confounding factors and placebo effects were excluded by the trial design. Other scientific approaches to this question provide supportive evidence that GH has direct effects on the CNS, affecting sleep patterns and the CSF concentrations of various neurotransmitters. The atypical nature of the depression, and the observation that GHD and its treatment does not alter CSF levels of 5HT or NE metabolites $(3,4)$, suggests that these symptoms may not be readily amenable to conventional antidepressant medication. The results of our study suggest that patients with $\mathrm{GH}$ deficiency and impaired QOL and/or atypical depression should be given a trial of GH therapy, and that the effects of treatment can be gauged after only a few months. Further research is needed to establish which GH treatment protocol and target IGF-I concentration provides maximum benefit in terms of QOL/depression, with minimal side-effects.

\section{Acknowledgements}

We would like to thank Rosemary Greenwood for statistical assistance and Moira Hunt for adjusting the growth hormone doses. This work was supported by grants from the Neuroendocrinology Charitable Trust, the Special Trustees of the United Bristol Healthcare Trust, and Pharmacia Upjohn Pharmaceuticals.

\section{References}

1 Carroll PV, Christ ER, Bengtsson B-A, Carlsson L, Christiansen JS, Clemmons D, Hintz R, Ho K, Laron Z, Sizonenko P, Sonksen PH, Tanaka T \& Thorne M. Growth hormone deficiency in adulthood and the effects of growth hormone replacement: a review. Journal of Clinical Endocrinology and Metabolism $1998 \mathbf{8 3} 382-395$.

2 Drake WM, Howell SJ, Monson JP \& Shalet SM. Optimizing GH therapy in adults and children. Endocrine Reviews 200122 425-450.

3 Burman P, Hetta J, Wide L, Mansson J-E, Ekman R \& Karlsson FA. Growth hormone treatment affects brain neurotransmitters and thyroxine. Clinical Endocrinology $199644319-324$. 
4 Johansson J-O, Larson G, Andersson M, Elmgren A, Hynsjo L, Lindahl A, Lundberg PA, Isaksson OG, Lindstedt S \& Bengtsson BA. Treatment of growth hormone deficient adults with recombinant human growth hormone increases the concentration of growth hormone in the cerebrospinal fluid and affects neurotransmitters. Neuroendocrinology 199561 57-66.

5 Price LH, Charney DS, Delgado PL \& Heninger GR. Serotonin function and depression: neuroendocrine and mood responses to intravenous L-tryptophan in depressed patients and healthy comparison subjects. American Journal of Psychiatry 1991148 1518-1525.

6 Puig-Antich J, Novacenko H, Davies M, Chambers WJ, Tabrizi MA Krawiec V, Ambrosini PJ \& Sachar EJ. Growth hormone secretion in prepubertal children with major depression. Archives of General Psychiatry 198441 455-460.

7 Birmaher B, Dahl RE, Williamson DE, Perel JM, Brent DA, Axelson DA, Kaufman J, Dorn LD, Stull S, Rao U \& Ryan ND. Growth hormone secretion in children and adolescents at high risk for major depressive disorder. Archives of General Psychiatry $200057867-872$.

8 Bulow B, Hagmar L, Orbaek P, Osterberg K \& Erfurth EM. High incidence of mental disorders, reduced mental well-being and cognitive function in hypopituitary women with $\mathrm{GH}$ deficiency treated for pituitary disease. Clinical Endocrinology $2002 \mathbf{5 6}$ 183-193.

9 Holmes S \& Shalet SM. Characteristics of adults who wish to enter a trial of growth hormone replacement. Clinical Endocrinology $199542613-618$.

10 Bryant J, Loveman E, Cave C, Chase D \& Milne R. Endocrinology trial design: adverse event reporting in randomised controlled trials of recombinant human $\mathrm{GH}$ in $\mathrm{GH}$ deficient adults. Journal of Endocrinology 2002175 545-552.

11 Wiren L, Whalley D, McKenna SP \& Wilhelmsen L. Application of a disease-specific, quality-of-life measure (OoL-AGHDA) in growth hormone-deficient adults and a random population sample in Sweden: validation of the measure by Rasch analysis. Clinical Endocrinology $2000 \mathbf{5 2} 143-152$.

12 Barkan AL. The 'Quality of life-assessment of growth hormone deficiency in adults' questionnaire: can it be used to assess quality of life in hypopituitarism? Journal of Clinical Endocrinology and Metabolism 200186 1905-1907.

13 Mahajan T \& Lightman S. A simple test for growth hormone deficiency in adults. Journal of Clinical Endocrinology and Metabolism 200085 1473-1476.

14 Goldberg D \& Hillier V. A scaled version of the General Health Questionnaire. Psychological Medicine 1979 9 139-145.

15 Goodchild ME \& Duncan-Jones P. Chronicity and the general health questionnaire. British Journal of Psychiatry $1985 \mathbf{1 4 6}$ $55-61$.

16 Wing J, Babor T, Brugha T, Burke J, Cooper J, Giel R, Jablenski A, Regier D \& Sartorius N. Schedules for clinical assessment in neuropsychiatry. Archives of General Psychiatry 199047 589-593.

17 World Health Organisation. The ICD-10 Classification of Mental and Behavioural Disorders. Diagnostic Criteria for Research. Geneva: World Health Organisation, 1993.

18 Hunt S \& McEwen J. The development of a subjective health indicator. Sociology of Health and Illness 19802 231-246.

19 Hunt SM, McKenna SP, McEwen J, Williams J \& Papp E. The Nottingham Health Profile: subjective health status and medical consultations. Social Science and Medicine 198115 221-229.

20 Hamilton M. Development of a rating scale for primary depressive illness. British Journal of Social and Clinical Psychology 19676 278-296.
21 Montgomery S \& Asberg M. A new depression scale designed to be sensitive to change. British Journal of Psychiatry 1979134 382-389.

22 Astrom C \& Trojaborg W. Effect of growth hormone on human sleep energy. Clinical Endocrinology 199236 241-245.

23 Murray RD \& Shalet SM. Adult growth hormone replacement: lessons learned and future direction. Journal of Clinical Endocrinology and Metabolism 200287 4427-4428.

24 Rosen T, Wiren L, Wilhelmsen L, Wiklund I \& Bengtsson B-A. Decreased psychological well-being in adult patients with growth hormone deficiency. Clinical Endocrinology $1994 \mathbf{4 0}$ 111-116.

25 Peace KA, Orme SM, Sebastian JP, Thompson AR, Barnes S, Ellis AW \& Belchetz PE. The effect of treatment variables on mood and social adjustment in adult patients with pituitary disease. Clinical Endocrinology 199746 445-450.

26 Lynch S, Merson S, Beshyah SA, Skinner E, Sharp P, Priest RG \& Johnston DG. Psychiatric morbidity in adults with hypopituitarism. Journal of the Royal Society of Medicine 199487 445-447.

27 Page RCL, Hammersley MS, Burke CW \& Wass JAH. An account of the quality of life of patients after treatment for non-functioning pituitary tumours. Clinical Endocrinology 199746 401-406.

28 McGauley GA, Cuneo RC, Salomon F \& Sonksen PH. Psychological well-being before and after growth hormone treatment in adults with growth hormone deficiency. Hormone Research 1990 33 (Suppl 4) 52-54.

29 Cuneo RC, Judd S, Wallace JD, Perry-Keene D, Burger H, Lim-Tio S, Strauss B, Stockigt J, Topliss D, Alford F, Hew L, Bode H, Conway A, Handelsman D, Dunn S, Boyages S, Cheung NW \& Hurley D. The Australian multicenter trial of growth hormone $(\mathrm{GH})$ treatment in GH-deficient adults. Journal of Clinical Endocrinology and Metabolism $1998 \mathbf{8 3} 107-116$.

30 Murray RD, Skillicorn CJ, Howell SJ, Lissett CA, Rahim A \& Shalet SM. Dose titration and patient selection increases the efficacy of GH replacement in severely GH deficient adults. Clinical Endocrinology $199950749-757$.

31 Drake WM, Coyte D, Camacho-Hubner C, Jivanji NM, Kaltsas G, Wood DF, Trainer PJ, Grossman AB, Besser GM \& Monson JP. Optimizing growth hormone replacement therapy by dose titration in hypopituitary adults. Journal of Clinical Endocrinology and Metabolism 199883 3913-3919.

32 Gilchrist FJ, Murray RD \& Shalet SM. The effect of long-term untreated growth hormone deficiency (GHD) and 9 years of GH replacement on the quality of life (QoL) of GH-deficient adults. Clinical Endocrinology 200257 363-370.

33 Whitehead HM, Boreham C, McIlrath EM, Sheridan B, Kennedy L, Atkinson $\mathrm{AB} \&$ Hadden DR. Growth hormone treatment of adults with growth hormone deficiency: results of a 13-month placebocontrolled cross-over study. Clinical Endocrinology $1992 \quad 36$ 45-52.

34 Baum HBA, Katznelson L, Sherman JC, Biller BMK, Hayden DL, Schoenfeld DA, Cannistraro KE \& Klibanski A. Effects of physiological growth hormone $(\mathrm{GH})$ therapy on cognition and quality of life in patients with adult-onset GH deficiency. Journal of Clinical Endocrinology and Metabolism 199883 3184-3189.

Received 7 January 2004

Accepted 31 May 2004 